\title{
Teoria das finanças funcionais e o papel da política fiscal: uma crítica pós-keynesiana ao novo consenso macroeconômico
}

\author{
GABRIEL CALDAS MONTES \\ ROMULO DO COUTO ALVES*
}

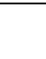

Theory of functional finance and the role of fiscal policy: A post-keynesian critique to the new consensus macroeconomics. This paper presents the critical approaches and elaborates the arguments that oppose those of the New Consensus Macroeconomics regarding the conduct of fiscal policy. Those criticisms and arguments are based in the post-Keynesian thought and the theory of Functional Finance. The theory of Functional Finance is an extension of the Keynesian approach, particularly with regard to discussions on public finances. As supports the theory of Functional Finance, the objectives to be pursued by fiscal policy should suggest the improvement of social welfare as a whole, i.e., the performance of inflation, employment and output should be taken into account by policymakers.

Keywords: fiscal policy; functional finance; post-Keynesian.

JEL Classification: E12; E62; H63.
\end{abstract}

\section{INTRODUÇÃO}

O desenvolvimento recente da macroeconomia ortodoxa, com destaque para as correntes monetarista e novo-clássica, pode ser considerado como a base para a condução de políticas econômicas pautadas em regras e, por sua vez, do surgimento do regime de metas de inflação. Destas duas escolas destacam-se três pontos

\footnotetext{
* Professor do Programa de Pós-Graduação em Economia da Universidade Federal Fluminense e Bolsista de Produtividade do CNPq. E-mail: gabrielmontesuff@yahoo.com.br; Mestre em Economia pela Universidade Candido Mendes. E-mail: romulo.couto@globo.com. Submetido: 25/março/2010; Aprovado: $10 /$ outubro/2011.
} 
de consenso (absorvido posteriormente pelo pensamento novo-keynesiano), que foram fundamentais para o desenvolvimento e aperfeiçoamento do regime de metas de inflação:

a) a visão de que a Curva de Phillips é vertical no longo prazo (inexistência de trade-off entre inflação e desemprego), ou seja, que os efeitos da política monetária sobre o setor real da economia, no longo prazo, é nulo, resultando apenas em mais inflação;

b) o problema de inconsistência temporal gerado por políticas monetárias discricionárias, e;

c) a construção de argumentos favoráveis à necessidade de estabilidade de preços para que o crescimento econômico seja promovido, haja vista a inflação deixar as economias mais sensíveis às crises, fragilizar o sistema financeiro, deteriorar as receitas do governo, distorcer preços relativos (com impactos distributivos perversos) e gerar ineficiência na alocação dos recursos.

Nesse regime, o papel da política fiscal fica limitado a uma posição secundária, servindo para não criar "surpresas ruins" para a gestão da política monetária. Ou seja, a política fiscal perde seu papel de grande instrumento de gestão de demanda agregada, conforme trabalhado em Keynes, para ter um papel secundário de criar as condições propícias de credibilidade e estabilidade da política macro, passando a política monetária, por meio do regime de metas de inflação, a ser a principal forma de se trabalhar a política econômica.

Nesse sentido, no presente trabalho serão apresentadas as abordagens críticas e elaborados os argumentos que se contrapõem àqueles do Novo Consenso Macroeconômico (NCM) quanto à condução da política fiscal. Tais críticas e argumentos encontram-se baseados no pensamento pós-keynesiano e na Teoria das Finanças Funcionais (TFF) - a qual tem como figura central Abba Lerner. A TFF representa uma extensão da abordagem keynesiana, sobretudo no tocante às discussões sobre finanças públicas ${ }^{1}$. Com a apresentação destas abordagens, tem-se um aparato teórico consistente para se criticar as abordagens ortodoxas das finanças públicas, principalmente o NCM.

Para tanto, além dessa introdução, o presente trabalho encontra-se dividido da seguinte maneira: na segunda seção, com base em uma perspectiva pós-keynesiana, é discutido o papel da política fiscal e das finanças públicas, como também são preparados os argumentos que justificam os princípios apresentados pela TFF; na terceira seção é apresentada a TFF e, com base nela, são elaboradas as críticas ao NCM e apresentadas as propostas alternativas. Por fim são apresentadas as conclusões do trabalho.

\footnotetext{
${ }^{1}$ Segundo Dos Santos (2005, p. 14), “Lerner completou a revolução keynesiana ao tornar as teorias das finanças públicas coerentes e, portanto, funcionais com a premissa de desemprego estável. As finanças funcionais são apenas o keynesianismo levado às últimas consequências".
} 


\section{O RESGATE DA ABORDAGEM DE KEYNES: FINANÇAS PÚBLICAS E OS PÓS-KEYNESIANOS}

A partir de meados da década de 1970, alguns economistas ${ }^{2}$ tentam resgatar as bases do pensamento de Keynes, dada a insatisfação com os desdobramentos apresentados pela abordagem neokeynesiana. Segundo Carvalho (2008, p. 2):

"Mesmo críticos menos ambiciosos (ou, talvez, melhor informados) tenderam a identificar o keynesianismo com uma proposição acima de todas as outras: a legitimidade do uso constante de déficits fiscais como arma de promoção da prosperidade econômica. Para esses comentaristas, a essência da política econômica keynesiana estaria na despreocupação com a geração continuada de déficits fiscais e, assim, na corrosão da noção de que a indisciplina fiscal possa ter qualquer efeito danoso sobre uma economia de mercado.”

Assim, a corrente pós-keynesiana ${ }^{3}$ desenvolveu-se com o objetivo fundamental de recuperar efetivamente a essência do pensamento de Keynes, notadamente o papel da incerteza, das expectativas e das políticas econômicas em suas obras, além de evitar qualquer tentativa de junção com a chamada ortodoxia marginalista.

Diante das críticas dos economistas associados à reação conservadora ${ }^{4}$, de que o legado do pensamento de Keynes havia fracassado, os pós-keynesianos (dentre os quais, Davidson, 1978 e Kregel, 1985) vão tentar mostrar que na verdade o fracasso deveria ser creditado a um tipo de leitura - equivocado certamente — da obra de Keynes.

No tocante às finanças públicas, particularmente, a posição dos pós-keynesianos vai seguir aqueles pontos levantados por Keynes ${ }^{5}$. Ou seja, permanece a ideia de que o importante, em termos de política fiscal, não é a geração de déficits, mas sim o papel do gasto público na complementação de uma demanda efetiva insuficiente. Carvalho (2008, p. 14) chama a atenção para esta questão ao recuperar a posição de Keynes para a intervenção do Estado:

\footnotetext{
${ }^{2}$ Dentre os principais autores podemos citar Hyman Minsky, Paul Davidson, Jan Kregel, Victoria Chick e Fernando Cardin de Carvalho.

${ }^{3}$ Vamos aqui nos referir aos chamados pós-keynesianos ou pós-keynesianos fundamentalistas, que procuram recuperar os aspectos fundamentais dos escritos originais de Keynes. Existe outro bloco que tenta recuperar o pensamento de Keynes na década de 1970, os keynesianos neo-ricardianos, que realizam uma leitura clássico-sraffiana da obra de Keynes. Para maiores informações sobre esta questão ver Lima (1992, especialmente capítulos 4 e 5).

${ }^{4}$ Aqui estamos falando essencialmente das críticas de monetaristas, como Friedman (1956, 1968, 1985) e novo-clássicos, com Lucas (1973), Lucas e Sargent (1981).

${ }^{5}$ Contudo, como alerta Kregel (1985), a passagem da obra de Keynes para os dias atuais não pode ser direta, levando à necessidade de adaptá-la às mudanças verificadas na economia capitalista e as especificidades de cada país em que a análise da política fiscal for aplicada.
} 
"É neste quadro que se define a intervenção do Estado na visão de Keynes. Economias empresariais dependem da disposição de empresários de produzir (e investir). Esta disposição diminuirá sempre que houver razões para temer-se que a demanda agregada será insuficiente para absorver a produção ou quando o futuro se tornar excessivamente opaco para permitir que se façam previsões de demanda com algum grau de confiança. Nesse caso, ao invés de converter seus recursos monetários em fatores de produção, eles preferirão retê-los na forma de moeda. O temor da demanda futura reduzida reduz o emprego no presente e os empresários verão suas piores expectativas confirmadas. De acordo com Keynes, isto ocorre porque se trata de uma economia monetária: uma economia em que a moeda é uma forma de riqueza, alternativa a outros ativos, inclusive bens de capital e fatores de produção. Quando o rendimento esperado destes últimos não for adequado ou for muito incerto, muitos empresários buscarão refúgio na acumulação de dinheiro, e o emprego e o nível de atividades declinarão.”

Nesse sentido, a política fiscal teria papel fundamental a partir do momento em que os empresários diminuam seus gastos de investimento. Ao se utilizar dos seus gastos, o governo levaria o setor privado a se mobilizar para gastar mais 6 .

A forma de operação da política fiscal, para os pós-keynesianos, se dá por meio das mudanças na tributação (que afetam a renda disponível do setor privado, induzindo os agentes a gastar mais ou menos), das variações nos gastos ou da combinação das duas. Por sua vez, o multiplicador do gasto público tem, para os pós-keynesianos, um impacto similar ao multiplicador dos gastos de investimento.

Também como em Keynes, os pós-keynesianos, na sua grande maioria, não fazem alusão à necessidade de que sejam mantidos déficits públicos ${ }^{7}$. Estes somente seriam admitidos em última instância, quando o gasto público efetivado, coberto pelas receitas, não fosse suficiente para ativar a demanda agregada.

Vale ressaltar que, para que as ações de política fiscal possam acontecer, faz-se necessário, segundo Carvalho (2008), dedicar a devida atenção aos seguintes elementos, pois, caso contrário, invalidariam os resultados:

a) estado das expectativas dos agentes - a ideia é que os agentes captem as sinalizações da política fiscal de forma positiva, transformando esses gastos inicialmente feitos pelo governo em novos gastos privados;

grau de utilização da capacidade produtiva - a política fiscal não deve ser ativada quando a economia estiver no pleno emprego. Caso a economia já esteja nesse ponto, os efeitos esperados da política fiscal seriam apenas

\footnotetext{
${ }^{6}$ É o que Carvalho (2008) ressalta ser a essência da política econômica keynesiana, ou seja, uma política de mobilização de recursos e não de alocação.

${ }^{7}$ Ver Kregel (1985); Davidson (1994); Carvalho (2008).
} 
inflacionários. Esta questão remete à observação de Keynes sobre a importância dos dois orçamentos, o de gastos correntes e o de capital ${ }^{8}$. A ênfase dos pós-keynesianos recai sobre o orçamento de capital, que segundo eles teria impacto maior sobre a economia, além de maior capacidade de discricionariedade quando do aumento de déficits fiscais ${ }^{9}$, e;

b) estado dos mercados de capitais - essa questão afeta diretamente a maneira pela qual ocorre o financiamento da dívida do governo, sendo o grande problema os agentes aceitarem os papéis do governo de maneira a financiar seus gastos.

Assim, os pós-keynesianos, propensos a recuperar o pensamento de Keynes, veem a questão fiscal como um instrumento a ser usado para impulsionar a economia. Não se advoga a permanência de déficits estruturais, mas sim a importância do aumento dos gastos públicos em momentos em que a economia se encontra em situação de contração. Neste caso, não se pode pensar em redução de gastos, pois os efeitos sobre a economia seriam desastrosos.

Ademais, não há na visão dos pós-keynesianos qualquer tipo de alusão a geração de déficits permanentes. A ação de política fiscal deve ser, antes de tudo, cuidadosamente planejada, de maneira a evitar desequilíbrios significativos que impeçam a sua utilização nos momentos de maior necessidade. Segundo Oreiro e De Paula (2009), a política fiscal deve: "a) gerar equilíbrio intertemporal do orçamento público; b) apoiar-se na realização de investimentos públicos como 'estratégia preventiva' para a estabilização do nivel de demanda efetiva”.

Sendo assim, não existe nenhum tipo de incompatibilidade em se incorporar ao pensamento de Keynes as questões associadas à disciplina fiscal, equilíbrio orçamentário e estratégia de redução do endividamento público.

\section{A TEORIA DAS FINANÇAS FUNCIONAIS}

Uma abordagem crítica mais profunda, ainda dentro da lógica keynesiana, é o da Teoria das Finanças Funcionais (doravante TFF). A TFF é construída, conforme mencionado, a partir do aparato teórico keynesiano e tem como ideia básica que as políticas fiscal e monetária devem ser avaliadas exclusivamente com base

\footnotetext{
${ }^{8}$ Segundo Carvalho (2008, p. 22), “[...] a elaboração de dois orçamentos é a separação entre o cumprimento das funções rotineiras do Estado e a realização de seus gastos discricionários. A diferenciação que importa reside na possibilidade de adiamento dos gastos de forma a contrarrestar as forças cíclicas da economia”.

${ }^{9}$ Segundo Oreiro e De Paula (2009): “[...] observa-se que o elemento mais importante da política fiscal anticíclica keynesiana não é a simples geração de déficits fiscais para estimular a economia, entendida como necessária em ocasiões de aguda desaceleração econômica, mas sim o aumento significativo da participação do investimento público no investimento total como expediente para a estabilização do investimento e da demanda efetiva".
} 
nos seus resultados econômicos, não devendo ser determinadas a partir de doutrinas que estabeleçam de forma apriorística o que é ou não saudável. Este tipo de abordagem defende, caso necessário, a determinação de um déficit público que induza a economia à utilização máxima dos recursos produtivos, respeitando, obviamente, a manutenção de um desempenho apropriado em termos de comportamento dos preços. Desta forma, qualquer Estado que tem o poder de emitir moeda própria não apresenta constrangimentos para fazer gastos públicos sem gerar impactos inflacionários. Nas palavras de Rodrigues (2004; os. 13-14):

“[...] tendo como princípio o chamado "pessimismo das elasticidades”, ou seja, o investimento privado é incapaz de reagir à redução das taxas de juros sendo, por essa razão, incapaz de levar a economia ao pleno emprego, mesmo que todos os pressupostos da teoria marginalista sejam respeitados. Desta forma, o foco da política econômica deve ser a forma como o governo deve elaborar suas finanças com o objetivo de manter a economia o mais próximo possível do seu nível potencial, tentando evitar desemprego involuntário e o processo inflacionário (provocado pela demanda).

As finanças do governo têm que ter uma funcionalidade macroeconômica e não devem ser consideradas apenas como a contabilização de entrada e saída de recursos cujo resultado final deve apresentar um equilíbrio financeiro."

A base da TFF são os trabalhos do economista Abba Lerner ${ }^{10}$ e está calcada no princípio da demanda efetiva, iniciado por Keynes. Atualmente a TFF tem como um dos seus maiores expoentes Randall Wray ${ }^{11}$.

O trabalho de Lerner tinha um viés crítico daquilo que se chamava a sua época de "Finanças Saudáveis", ou seja, a ideia preestabelecida de que os governos deveriam perseguir orçamentos equilibrados e restringir aumentos da dívida públi$\mathrm{ca}^{12}$. Segundo Lerner (1943, p. 298):

\footnotetext{
${ }^{10}$ Ver Lerner (1941, 1943 e 1951), Forstater (1999) e Wray (2003) para maiores informações. Uma importante referência também acerca da Teoria das Finanças Funcionais é o trabalho de Nell e Forstater (2003), composto de uma coletânea de artigos de diversos autores que tratam da relação existente entre a teoria das finanças funcionais com diferentes outras questões. Ressalte-se que no artigo de 1941 Lerner apresenta pela primeira vez os princípios das Finanças Funcionais, no qual faz uma analogia com a direção de um carro com os controles que o governo têm para dirigir a economia. Mas é no artigo de 1943 que Lerner vai detalhar de forma mais consistente sua teoria.

${ }^{11}$ Wray é economista do Levy Institute-EUA, sendo que este instituto concentra um número significativo de economistas que podem ser associados à TFF, por exemplo, Mathew Forstater e Pavlina Tcherneva.

${ }^{12}$ Colander (2002, p. 2) ressalva que o termo "Finanças Funcionais" foi o nome dado por Lerner para a abordagem teórica de finanças do governo de acordo com as seguintes três regras: " 1 . The government shall maintain a reasonable level of demand at all times. If there is too little spending and, thus, excessive unemployment, the government shall reduce taxes or increase its own spending. If there is too much spending, the government shall prevent inflation by reducing its own expenditures or by increasing
} 
"The central idea is that government fiscal policy, its spending and taxing, its borrowing and repayment of loans, its issue of new money and its withdrawal of money, shall all be undertaken with an eye only to the results of these actions on the economy and not to any established traditional doctrine about what is sound and what is unsound. This principle of judging only by effects has been applied in many other fields of human activity, where it is known as the method of science opposed to scholasticism. The principle of judging fiscal measures by the way they work or function in the economy we may call Functional Finance."

Isso porque, para a chamada "Finanças Saudáveis", a economia estaria sempre em pleno emprego e, ao efetuar suas despesas, o governo estaria deslocando gasto privado (efeito crowding out). Segundo Rodrigues (2004, p. 14), para a TFF:

"Não existe razão para acreditar que a economia esteja produzindo ao seu nível potencial, nem que ela tenderá no longo prazo para este nível determinado pela oferta (como postulado pela teoria neoclássica). A aplicação do princípio da demanda efetiva no longo prazo demonstra que a produção se adapta a demanda e, dentro dessa abordagem o gasto autônomo do governo influencia diretamente a demanda agregada no longo-prazo e, consequentemente, a evolução da própria capacidade produtiva."

E neste aspecto Lerner criticava tanto a ortodoxia quanto os neokeynesianos no tocante à capacidade de compatibilização dos pressupostos das "Finanças Saudáveis" com o desemprego estável. Nas palavras de Dos Santos (2005, p. 14):

"Provavelmente o principal objetivo de Lerner ao construir sua teoria das Finanças Funcionais tenha sido mostrar quais seriam as reais limitações ao gasto e endividamento públicos. Esse objetivo está relacionado à escolha do nome dessa teoria. As Finanças Funcionais são, antes de tudo, uma crítica às Finanças Saudáveis. Mas não apenas uma crítica à teoria econômica ortodoxa em que se baseiam as Finanças Saudáveis. Lerner visava criticar também a incoerência dos keynesianos e população em geral quando acreditam ao mesmo tempo nas Finanças Saudáveis e na possibilidade de desemprego estável.”

Assim, a TFF rejeita completamente qualquer possibilidade de incorporar dentro de suas premissas os princípios básicos da chamada "Finanças Saudáveis", mais

taxes; 2. By borrowing money when it wishes to raise the rate of interest and by lending money or repaying debt when it wishes to lower the rate of interest, the government shall maintain that rate of interest that induces the optimum amount of investment; 3. If either of the first two rules conflicts with the principles of 'sound finance' or of balancing the budget, or of limiting the national debt, so much the worse for these principles. The government press shall print any money that may be needed to carry out rules 1 and 2 ". 
especificamente a ideia de objetivar um orçamento fiscal equilibrado. Nas palavras de Lerner (1943, p. 41) "In brief, Functional Finance rejects completely the traditional doctrines of 'sound finance' and the principle of trying to balance the budget over a solar year or any other arbitrary period".

Segundo Wray, Lerner assim resumiu os objetivos básicos da Teoria das Finanças Funcionais:

"Finanças Funcionais [...] prescreve: primeiro o ajustamento do dispêndio total (por todos na economia, incluindo o governo) a fim de eliminar tanto o desemprego quanto a inflação, usando o dispêndio governamental quando o dispêndio total é muito baixo e a tributação quando o dispêndio total é muito alto; segundo, o ajustamento da quantidade de dinheiro e de títulos governamentais em poder do público, pela tomada de empréstimos ou pagamento de dívida, a fim de alcançar a taxa de juros que resulta no nível mais desejável de investimento; e, terceiro, a impressão, armazenamento ou destruição de moeda à medida que for necessário para implementar as duas primeiras partes do programa" (Lerner, 1943, p. 41, apud Wray, 2003, p. 96)

Assim, o papel da política fiscal, mais precisamente do gasto público, é ajustar as decisões de gastos dos agentes privados no sentido de gerar a plena utilização dos recursos produtivos. Sendo assim, o nível de impostos deve ser determinado pelo volume de gastos privados compatíveis com o pleno emprego ${ }^{13}$. A dívida pública deve ser gerida de maneira a que o setor privado possa ajustar seu portfólio à taxa de juros fixada pelo banco central.

Embora bastante voltada para o caso dos países desenvolvidos, principalmente para a economia americana, deve-se atentar que ainda assim é uma boa opção a ser aprofundada para países que sofrem de problemas de restrição externa e inflação ${ }^{14}$.

Segundo Dos Santos (2005, p. 16), para se compreender as propostas da TFF é necessário se ter em mente "as consequências da liberdade e do monopólio estatal de emissão de moeda". Lerner seguia, neste caso, a teoria cartalista. Segundo Wray (2003, p. 38):

"Na abordagem cartalista, o dinheiro é uma criatura do Estado; ao menos no caso do dinheiro moderno, sendo difícil de ocorrer exemplos de dinheiro sem Estado. O Estado define dinheiro como aquilo que se

\footnotetext{
${ }^{13}$ Lerner se refere ao conceito de pleno emprego da seguinte forma: "Full employment means only that those who want to work at the prevailing rates of pay are able to find work without undue difficulty". Ver Lerner (1951, p. 17). Vale ressaltar que Lerner chega a sugerir a utilização de técnicas menos intensivas em trabalho para que fosse possível a utilização de um número maior de trabalhadores (ver Lerner: 1951, os. 143 e 144).

${ }^{14}$ Para maiores detalhes ver Dos Santos (2005), principalmente capítulo 4.
} 
aceita nos guichês públicos de pagamento (principalmente em pagamento de tributos). Isto tem importantes implicações políticas. Uma vez que o Estado impõe um tributo aos seus cidadãos, pagável numa moeda sobre a qual tem um monopólio de emissão, ele pode influenciar o valor daquela moeda estabelecendo as condições sob as quais a população pode obtê-la. O governo não tem 'necessidade' do dinheiro do público para gastar; ao contrário, o público necessita do dinheiro do governo para pagar tributos. Isso significa que o governo pode 'comprar' qualquer coisa que esteja à venda em termos de seu dinheiro, apenas pelo fornecimento desse dinheiro.”

Para Lerner (1947, p. 313):

"The modern state can make anything it chooses generally acceptable as money and thus establish its value quite apart from any connection, even of the most formal kind, with gold or backing of any kind. It is true that a simple declaration that such and such is money will not do, even if backed by the most convincing constitutional evidence of the state's absolute sovereignty. But if the state is willing to accept the proposed money in the payment of taxes and other obligations to itself the trick is done. Everyone who has obligations to the state will be willing to accept the pieces of paper with which he can settle the obligations, and all other people will be willing to accept those pieces of paper because they know that taxpayers etc., will accept them in turn. On the other hand if the state should decline to accept some kind of money in payment of obligations to itself, it is difficult to believe that it would retain much of its general acceptability [...] What this means is that whatever may have been the history of gold, at the present time, in a normally well-working economy, money is a creature of the state. Its general acceptability, which is its all-important attribute, stands or falls by its acceptability by the state."

Ou seja, é o Estado quem define o que será usado como moeda, tendo a capacidade de gastar mais do que arrecada e até mesmo de arrecadar antes de gastar. Ademais, o Estado deve gastar mais do que arrecada, devendo ser esta a norma corrente na sociedade. Sendo assim, é possível utilizar a política fiscal para aumentar o nível de emprego e controlar a inflação, como sugere Lerner (1943, p. 40):

"Government should adjust its rates of expenditure and taxation such that total spending in the economy is neither more nor less than that which is sufficient to purchase the full employment level of output at current prices."

Trabalhando de acordo com a lógica keynesiana, Lerner chama a atenção da incapacidade do setor privado conseguir, sozinho, gerar as condições para que o pleno emprego surja. Desta forma, o governo surge como um elemento importan- 
te para fazer frente à insuficiência de demanda efetiva. Wray (2003, p. 23) chama atenção para este ponto:

"Porque o público necessita do dinheiro do governo (exigibilidades do governo, que são moedas), ele vai querer fornecer coisas para o governo a fim de obter twintopt. Assim como as pessoas lutariam para obter peles de castor se estas fossem o twintopt exigido, os cidadãos nas economias modernas esforçam-se para obter moeda a fim de pagar os tributos. Isso significa que o governo pode, se assim escolher, estabelecer os termos em que a moeda pode ser obtida (isto é, o esforço necessário para obtê-la). Não teria sentido para o governo impor um tributo e depois recusar-se a oferecer a moeda necessária, pois isso poderia significar a prisão dos cidadãos por evasão fiscal! No mínimo, o governo terá de assegurar a oferta de um montante de moeda igual às obrigações tributárias a longo prazo. Na verdade, provavelmente, poderia, sem perigo, fornecer mais moeda que o estritamente necessário para os tributos. Muitos cidadãos ficariam felizes de acumular pequenas reservas de moeda extra num dado ano, para o caso de ser mais difícil obter moeda nos anos seguintes, e também para o caso de perder algum dinheiro na troca. O caso 'normal', então, é o governo 'incorrer em déficit', isto é, fornecer mais moeda do que ele recolhe em tributos. Repetindo, nas economias modernas, o dinheiro de cunho forçado [...] é sempre moeda" ${ }^{15}$.

Portanto, para a TFF, o gasto público é variável fundamental para que a economia vá para a trajetória do pleno emprego ${ }^{16}$. Segundo Dos Santos (2005, p. 17):

"O déficit público é fundamental para atender as demandas das pessoas, bancos e empresas por moedas para transacionarem ou entesourarem. Em uma visão de finanças funcionais, o déficit público não é necessário simplesmente para prover a demanda por moeda. Ele é necessário para prover a "demanda" por renda dos desempregados."

E, segundo Lerner, os ganhos com o pleno emprego são bastante significativos, tanto no plano econômico quanto no social. Citando o texto de Lerner de 1951, Forstater (1999, p.1) ressalta esses aspectos:

\footnotetext{
15 Twintopt é uma expressão cunhada por Wray e significa aquilo necessário para pagar tributos. Esses tributos são cobrados na moeda do próprio Estado, que representa uma exigibilidade do governo. Destarte, o Estado estabelece os termos em que a moeda pode ser obtida. Sendo assim, todos os Estados se reservam o direito de determinar o twintopt e, na maioria das economias que funcionam sem maiores abalos, o twintopt faz uso do dinheiro. Esta lógica leva à idéia de que o é o público que precisa do "dinheiro do governo" para saldar tributos e não o governo que necessita do dinheiro do público para gastar.

${ }^{16}$ Assim como já aparecia em Keynes, como também em Kalecki, o gasto do governo (consumo e investimento), como os gastos do setor privado são variáveis chaves que comandam a demanda e, consequentemente, a renda.
} 
"Lerner's arguments for full employment are worth reviewing. First, the economic gains from full employment are enormous (1951, pp. 31-32). The costs of unemployment are staggering. These include the permanent loss of output of goods and services, but also the social costs resulting from increased crime, illness, and other social problems.

Full employment increases efficiency. By removing the threat imposed on workers by the existence of a reserve army of unemployed, workers will feel more confident to move out of one job and into another. This often means a movement from a lower productivity job to a higher productivity job (1951, p. 32).

Individual economic security is an even more important benefit than the increase in goods and services $(1951$, p. 33). Though this means foremost individual economic security for workers, government commitment to full employment has an important stabilizing impact on business confidence, derived from the awareness that the state is committed to maintaining aggregate demand (1951, p. 33).

[...]

Full employment is key to social stability (1951, pp. $37 \mathrm{ff}$.$) . Without$ employment and income security, citizens are vulnerable to dangerous ideologies, scapegoating, and anti-democratic political movements."

Assim, o papel da política fiscal, mais precisamente do gasto público, é ajustar as decisões de gastos dos agentes privados no sentido de gerar a plena utilização dos recursos produtivos. Logo, o nível de impostos deve ser determinado pelo volume de gastos privados compatíveis com o pleno emprego. A dívida pública, por sua vez, deve ser gerida de maneira a que o setor privado possa ajustar seu portfólio à taxa de juros fixada pelo banco central, de forma que não há qualquer necessidade de metas fixas na relação entre gastos e arrecadação.

Wray coloca como uma das questões centrais da TFF o fato de que o governo não recolhe tributos primariamente para pagar suas despesas. $\mathrm{Na}$ verdade o que ocorre é efetivamente o contrário, ou seja, o governo emite moeda (ou dívida) para comprar bens e serviços, a fim de permitir à sociedade pagar tributos.

Nas economias modernas, o governo define o dinheiro como forma de pagamento dos tributos pelo público. Sendo assim, segundo Wray (2002, p. 193):

"Qualquer Estado soberano com capacidade de impor tributos estará apto a emitir moeda fiduciária, a definir exogenamente a taxa de juros básica e a financiar seus gastos na aquisição de bens e serviços mediante a criação de reservas bancárias, não sendo necessário que o Estado se endivide antes de gastar."

Essa capacidade de "impor" impostos permite ao Estado, dado ser o mesmo livre emissor de sua própria moeda, por meio do Tesouro, realizar gastos públicos de forma não inflacionária, sem qualquer necessidade de estabelecimento de metas 
fixas na relação entre gastos e arrecadação. Ou seja, o valor do déficit ou da dívida pública não é restrição à capacidade de gasto do Estado ${ }^{17}$.

É importante ressaltar esta questão. Quando o governo emite moeda ou títulos e "impõe" impostos tem como objetivo realizar o funcionamento da economia, de maneira a levar a economia ao pleno emprego com estabilidade. Quando realiza seus gastos (investimentos e gastos de custeio), não há a necessidade de se estabelecer um orçamento prévio, discriminando como vai ser a forma de cobertura de impostos. O orçamento público, seguindo a lógica da TFF, é visto como uma peça contábil em que são discriminadas as intenções de gastos, não sendo visto como uma restrição econômica efetiva.

Quando o orçamento "ex-post” apresenta déficit, pode-se depreender, na verdade, que o setor privado está mais intencionado a reter ativos financeiros públicos como reserva de valor e não fazer gastos, o que implica a não geração de base para que a arrecadação aumente. Quando o orçamento "ex-post" se apresenta superavitário, pode-se deduzir que o gasto público induziu o setor privado a gastar mais, e, por conseguinte, gerou grande aumento da arrecadação ${ }^{18}$.

Assim, diferente da visão corrente na ortodoxia, como também do senso comum, o governo não cria impostos para se financiar, pois os gastos se autofinanciam. Dado, como colocado anteriormente, a moeda ser "uma criatura do Estado", as decisões de tributação devem ser vistas apenas sob seus efeitos em termos de promoção de pleno emprego e estabilidade de preços. Segundo Dos Santos $(2005$, p. 26):

"Os impostos não servem para financiar o Estado no sentido de recolher moeda que possa ser utilizada em pagamentos, já que ele emite a moeda que usa em pagamentos. A importância primária dos impostos é: (1) definir qual a unidade ou moeda de conta (real, dólar etc.), (2) definir o que é o dinheiro que corresponde à unidade de conta (aqueles pedaços de papel com determinadas características), (3) criar a razão primária para a demanda por moeda nacional e (4) sustentar a razão para a demanda por moeda pela criação de uma 'dívida' flexível, não contabilizada e crescente do setor privado (sob autoridade do Estado) com o Estado. É essa 'dívida' que garantirá, em última instância, que qualquer uma expansão na oferta de títulos públicos decorrente de uma expansão nos gastos públicos terá demanda e que todo crescimento econômico puxado pelo déficit público (gastos) é sustentável desde que exista desemprego, não importando qual seja o tamanho da dívida governamental.”

\footnotetext{
${ }^{17}$ Isto pode ser percebido claramente ao longo da história mundial. Ademais, os acontecimentos recentes, ou seja, a crise que estourou na economia mundial a partir de setembro de 2008 , corroboram esta tese. ${ }^{18}$ Isto é bastante diferente, neste último caso, de se atribuir este superávit a uma firme conduta do governo no sentido de se mostrar uma "austeridade responsável” no manejo da política fiscal.
} 
De acordo com a TFF, ao realizar déficits públicos, o governo, além de gerar demanda efetiva, para promover crescimento econômico e pleno emprego, por meio de seu gasto, influencia a demanda do público por moeda e títulos por meio de novos empréstimos ou pagamento de dívida. Os títulos, então, oferecem uma alternativa remunerada à moeda. Ou seja, o aumento da dívida pública reflete o aumento da riqueza da sociedade, pois na medida em que essa acumula riqueza em investimentos imobilizados, como fábricas e casas, é necessário que se tenha uma base de liquidez para garantir as transações, o pagamento das dívidas, dos impostos e uma reserva precaucionária. Essas coisas só podem ser supridas por títulos ou moeda pública, porque os títulos privados estão sempre associados à dívida privada, não aumentando a liquidez da economia. Aumentar a dívida pública não é critério para restringir um investimento público.

Para Dos Santos (2005, p. 30):

"Podemos assim concluir que os déficits públicos pela emissão de moeda ou mesmo de títulos de dívida são fontes fundamentais de liquidez para o setor privado.

Ao contrário do que comumente se pensa, a política monetária não cumpre esse papel. Nas suas formas mais tradicionais essa política apenas troca ativos líquidos por outros, ou seja, não muda significativamente as condições de solvência e liquidez do setor privado. Para melhorar realmente a liquidez, é necessário aumentar a relação entre ativos líquidos e passivo dos agentes em geral. Isso significa que é preciso aumentar as rendas de uns sem reduzir a liquidez de outros. Apenas o déficit público, o superávit externo e uma aquisição líquida de ativos privados pelos bancos podem fazer isso. Nesse último caso, entretanto, se os bancos assim procederem, sem correspondente aumento do déficit público ou saldo em conta corrente, estariam piorando seus indicadores de solvência, pois tanto o indicador ativo/patrimônio líquido, quanto o indicador ativo/títulos públicos teriam se deteriorado".

Ademais, o propósito básico da dívida pública é regular a taxa de juros. Segundo Forstater (1999, p. 4):

"What is the purpose of government bond sales if not to fund government spending? For Lerner, the primary purpose of bond sales is to manage reserves and thus the overnight rate of interest (inter-bank lending rate) in the face of government fiscal operations. The government should sell bonds, writes Lerner, "if otherwise the rate of interest would be too low." (1943, p. 355)

Outro ponto importante, fundamental para Lerner e para a TFF, é que o orçamento público não deve ser visto como um fim em si mesmo (visão tão cara a nova ortodoxia e à mídia), mas sim como um meio para alcançar um determinado fim. Alguns autores, como Forstater chegam a mencionar que, dentro desta ótica, 
pode-se até aceitar a ideia de um orçamento equilibrado, se o mesmo for necessário para se alcançar o pleno emprego e/ou a estabilidade de preços. Isto fica explícito na passagem abaixo:

"Thus, Functional Finance does not say anything about what the budget should be prior to economic analysis. If it is concluded that under particular circumstances, a balanced budget describes the best means to economic prosperity, then even a balanced budget is not inconsistent with a functional approach to public finance. 'Sound money' is therefore only inconsistent with Functional Finance if the balanced budget is seen as an end in itself, rather than as a means to an end. If a balanced budget - or a surplus, to reduce the national debt - is insisted upon, even if it may be shown to have negative economic consequences (or be impossible), then this is not Functional Finance (it is, actually, 'dysfunctional finance'). Likewise, Functional Finance does not stipulate that bigger deficits are 'better' or that deficits are 'good', in and of themselves; what concerns us are the effects. "(Forstater, 2006, p. 6)

Vale ressaltar um aspecto importante levantado pela TFF. Está associado à capacidade de "impor" tributos por parte do governo. Pela abordagem convencional (que Lerner denomina de Finanças Saudáveis), o gasto somente pode ocorrer com tributação prévia por parte do governo. Pela TFF o gasto é realizado antes da arrecadação dos impostos, pois, caso contrário, os agentes não teriam recursos para pagar tributos, pois os mesmos são pagos com moeda emitida previamente pelo Estado. E para que este circuito se complete, é necessário que os tributos sejam menores do que os gastos feitos inicialmente pelo governo, de maneira que os recursos não retornem do setor privado para o governo.

Deste quadro pode-se perceber que a emissão de moeda ou "imposição" de tributos por parte do governo é uma forma do mesmo fazer com que a economia possa chegar ao pleno emprego. O orçamento público não é uma restrição econômica real. A geração de um déficit nos leva a concluir que o gasto público induziu o setor privado a gastar menos, não gerando aumento significativo na arrecadação de impostos. Por outro lado, a geração de um superavitário, nos mostra que o gasto público induziu o setor privado a gastar mais, gerando grande aumento de impostos.

Para exemplificar esta questão podemos recorrer à seguinte situação: um determinado governo quer desenvolver uma nova atividade. Para isso é necessário, inicialmente, fazer gastos, tanto operacionais ou de custeio (como, por exemplo, pagamento de pessoal, contratação de serviços de terceiros e contratação de materiais) e de investimentos. Esses gastos podem ser financiados pela emissão de moeda. Posteriormente, o governo tributa, ou mais precisamente, usa sua prerrogativa de “impor" impostos. De acordo com essa lógica, o déficit público é necessário para que o público detenha numerário em mãos, na forma de moeda para as transações ou em títulos públicos, no sentido de atender o desejo das pessoas de deter um instrumento público seguro de poupança. 
Assim, para Lerner, a ação do governo pode afetar a demanda agregada por meio de duas formas. Primeiramente por meio de seus gastos com bens de consumo e/ou bens de capital. Caso o governo decida aumentar esses gastos, estará aumentando a demanda agregada. Outra forma do governo agir é por meio da tributação ou de transferências. Qualquer alteração nesse caso leva à variação dos recursos disponíveis para consumo dos agentes, mais especificamente a renda disponível dos agentes ${ }^{19}$. Vale ressaltar que, no primeiro caso (ou seja, aumento ou diminuição de gastos), o governo estará afetando a demanda de forma direta, enquanto que, no segundo caso (aumento ou redução dos tributos e das transferências), de forma indireta, pois as ações vão afetar inicialmente a renda disponível das famílias para, então, posteriormente, afetar a demanda, pela variação no consumo.

E quanto à associação do déficit com a inflação, conforme colocado pela abordagem convencional, a TFF desconsidera, dado que os recursos estão associados ao aumento da capacidade produtiva, contribuindo de maneira deflacionária no médio prazo. A emissão de títulos públicos tem por finalidade oferecer mais um ativo como alternativa de aplicação da riqueza dos agentes, impactando o rendimento de suas carteiras e, por conseguinte, influenciando suas disposições de gasto em consumo e investimento.

Lerner não considera que o orçamento equilibrado seja uma medida necessária e nem mesmo eficaz contra a inflação. Assim, é possível dizer que a teoria da inflação é também fundamental para a compreensão da TFF. Não há nesta um viés inflacionário. Ressalte-se que um dos objetivos da TFF é a estabilidade de preços. A grande questão é que, em função de expectativas de que a inflação possa crescer, não se deve colocar a meta de orçamento equilibrado como o grande objetivo a ser alcançado.

Ademais, outro ponto ressaltado por Lerner é que a simples emissão de moeda não gera impactos na economia, inclusive em termos inflacionários. Conforme citado por Forstater (1999, p. 4), para Lerner, existiriam seis instrumentos fiscais (ou três pares de instrumentos): tributação e transferências, compra ou venda de bens, tomar ou emprestar dinheiro. "Imprimir dinheiro" não pode ser um ato independente desses, mas sim dependente a esses seis instrumentos fiscais. No trecho a seguir, Lerner deixa bem clara esta ideia:

"[T] he creation of money has no effects on the economy as long as the printed money remains in the print shop. It is only when the money gets out into the economy that any effects come about. Money which is newly created and kept locked up might as ell never have been created. (Lerner, 1951, p. 132)

\footnotetext{
${ }^{19}$ Um exemplo nítido disto pode ser encontrado neste período recente. Diante da desaceleração da economia, os governos abriram mão de receita, reduzindo tributos para determinados produtos, como automóveis e bens da construção civil. Programas como o Bolsa Família também são exemplos típicos de ações do governo que aumentam a renda disponível dos agentes.
} 
No mesmo texto, Lerner complementa esta questão:

"All the decisions of any importance are made when it is decided to apply the fiscal instruments [...] If any of the instruments involves the paying out of money [...], the effects are just the same whether the money paid out was previously resting in the treasury or whether it had to be printed because there was not enough available in the treasury to permit them to be carried out on the scale that was considered necessary to prevent deflation. The use of the instrument should never be hampered just because there may not be enough money stock in the treasury at the moment. To sacrifice the prevention of deflation because of shortage of money which could be printed is no more sensible than to refrain from carrying out any other important government action because the necessary paper forms or stationery would have to be printed". (Lerner, 1951, p. 133, apud Forstater, 1999, p. 5).

Por fim, vale ressaltar a importância de Wray em termos de avançar e revolucionar a TFF adicionando à mesma o conceito do Empregador de Última Instância (EUI). A ideia básica é a criação de um programa governamental de geração de trabalho àqueles que estiverem dispostos a trabalhar por um salário nominal de referência. A ideia é que este programa seria uma maneira eficaz de criar condições para a estabilidade de preços e aumento da renda, funcionando como um forte instrumento anticíclico. Wray, bem como os adeptos da TFF, consideram "antiético manter pessoas desempregadas dentro do conceito liberal da taxa natural de desemprego".

\section{CONCLUSÃO}

Essas considerações de natureza teórica e histórica são importantes tanto para se compreender o que Keynes realmente defendia no contexto do pós-guerra quanto para, ao analisar a natureza da crise fiscal e a expansão dos gastos públicos no Brasil, se ter capacidade de formular uma crítica heterodoxa consistente e, ao mesmo tempo, oferecer alternativas coerentes para lidar com os dilemas contemporâneos da política fiscal e macroeconômica. Não há como negar que existem esses dilemas, que perpassam desde a coordenação entre políticas monetária e fiscal até escolhas não triviais sobre os gastos públicos e a política tributária.

A visão convencional de condução da política econômica, representada essencialmente pelo NCM, tem sofrido, no período recente, críticas abertas até mesmo de autores que não se alinham com a visão keynesiana ${ }^{20}$.

\footnotetext{
${ }^{20}$ Forstater $(1999$, p. 1) chama a atenção para esta questão: "The Asian Crisis, with the fallout in Latin America and the transition economies; the Russian default; continuing troubles in Japan; weaknesses in the structure of the new European EMU; volatility on Wall Street; deflationary pressures in the global
} 
Vários são os pontos que têm sido questionados, tanto do ponto de vista teórico quanto da ação prática, no Brasil e no mundo. Dentre eles é possível citar:

I. a discussão sobre o próprio significado da crise fiscal, ou seja, suas origens e implicações;

II. a relação entre taxa de juros, geração de superávit primário e dívida pública;

III. os limites da lógica de necessidade de maiores superávits primários aumento da carga tributária - investimentos públicos deprimidos - necessidade de expansão dos gastos da seguridade social; e

IV. o papel do Estado, ou seja, a discussão sobre qual o tipo de Estado que se requer.

Uma análise de política fiscal ou econômica, como a que se pretende para o Brasil, não pode estar dissociada da perspectiva histórica e política do país e dos interesses envolvidos nas escolhas do governo. Ao contrário do que a ortodoxia prega, nenhuma decisão tomada na esfera pública é efetivamente neutra ou independente dos interesses em jogo, nem mesmo quando seguem "regras", como as vigentes hoje para a política fiscal e monetária.

Conforme sustenta a Teoria das Finanças Funcionais, os objetivos a serem perseguidos pela política fiscal devem sugerir a melhoria do bem-estar social como um todo, tanto no curto quanto no longo prazo, ou seja, tanto o desempenho para a questão da inflação quanto para o emprego e o produto devem ser levados em consideração pelos policymakers. O valor do déficit ou da dívida pública não pode ser colocado como uma restrição à capacidade de gastar do Estado, como pode se observar agora, diante da crise na economia mundial, na ação do governo dos Estados Unidos e de outros países centrais e periféricos.

Ademais, não se pode colocar uma camisa de força na questão das finanças públicas. Conforme colocado anteriormente, o orçamento não pode ser visto como um fim em si mesmo, mas sim como um instrumento ou uma ferramenta para se atingir um determinado fim. E isto tanto Keynes como os pós-keynesianos, aí se incluindo a TFF, fazem questão de ressaltar. Entretanto, os adeptos da TFF conseguem ir mais a fundo na crítica.

A TFF procura trabalhar com a ideia de que o objetivo da política econômica, e mais precisamente da gestão das finanças do governo, deve ser o de manter a economia o mais próximo possível do seu nível potencial, tentando evitar desemprego involuntário e o processo inflacionário.

Não existe razão para acreditar no postulado das teorias convencionais, den-

economy: recent economic developments invite a reconsideration of some of our most deeply held beliefs concerning economic theory and public policy. Even within the hallowed halls of mainstream economics, voices of dissent can be heard. Paul Krugman, Joseph Stiglitz, and Jeffrey Sachs are among those whose recent proclamations indicate that we have entered a period in which orthodox views are being openly questioned, creating an atmosphere characterized by a crisis of confidence". 
tro da ortodoxia econômica, de que a economia esteja sempre produzindo no seu nível potencial, ou mesmo que, no longo prazo, vá tender para este nível, de produto potencial, determinado pela oferta.

Tomando como base o princípio da demanda efetiva para o longo prazo, temos que a produção se adapta a demanda. Sendo assim, podemos perceber a importância do gasto autônomo do governo, pois, ao ser efetuado, influencia diretamente a demanda agregada e, consequentemente, no longo prazo, a trajetória da própria capacidade produtiva.

Assim, a gestão da política fiscal deve levar em consideração que as finanças do governo têm que ter funcionalidade macroeconômica, não se devendo considerá-las apenas como a contabilização de entrada e saída de recursos, cujo resultado final necessariamente deva ser o de apresentar um equilíbrio financeiro.

O fundamental é lembrar um grande legado que a TFF deixou e que hoje está cada vez mais esquecido: o de que o orçamento fiscal não pode ser encarado como um fim em si mesmo, mas como um meio para se alcançar determinados objetivos, como o pleno emprego e a estabilização ${ }^{21}$.

Ademais, devemos entender a TFF como uma abordagem que pode trabalhar com diversas políticas específicas, dependendo do espaço e do tempo a que estivermos analisando ${ }^{22}$.

\footnotetext{
${ }^{21}$ Nas palavras de Forstater $(1999$, p. 2): "This principle is so simple, yet apparently so difficult to understand. If one supports balancing the budget as the proper means to achieving some economic goal, this is entirely consistent with the principle of functional finance. It is not the balanced budget that is 'sacred,' it is simply a means to the ends that are desired. They should thus agree, in principle, that if some other relation between government expenditure and tax receipts were the best means to attaining those ends, the balanced budget should be abandoned and those other means instituted. But if one promotes a balanced budget as an end in itself-as the 'right' thing to do, it would be 'irresponsible' to do otherwise-without regard to the potential effects and the sacrifice of macro goals, this is not consistent with the principle of functional finance. This is best referred to as dysfunctional finance".

${ }^{22}$ Segundo Forstater (1999, p. 7): “There may be misconceptions that functional finance is equated with a particular policy, e.g., running a big deficit. Functional finance is rather a general approach within which a whole series of policies may be conducted. The actual policies which will be implemented will depend on the economic circumstances that exist at a particular time. Functional finance is an outlook that what matters are the effects of policies and not the policies themselves, which are mere means. Thus functional finance does not advocate big deficits under any and all circumstances, just as it does not view a balanced budget as inherently 'good' in and of itself, independently of its impact on the economy What functional finance advocates first and foremost is that policy be based on an understanding of the monetary and financial system in which we live, and not some idealized vision of some other system, or some system that may have existed at some other time. For example, if fiscal and monetary policy is formulated as if we were on a gold standard, we not only will sacrifice tremendous potential benefits, we may subject ourselves to grave danger. You cannot, and should not, run a fiat currency system by the logic of a metallic standard system".
} 


\section{REFERÊNCIAS BIBLIOGRÁFICAS}

CARVALHO, Fernando José Cardim de. Equilíbrio fiscal e política econômica keynesiana. Revista Análise Econômica, Porto Alegre, ano 26, n. 50, p. 7-25, setembro de 2008.

COLLANDER, David. Functional Finance, New Classical Economics and Great Great Grandsons. Middlebury College Economics Discussion Paper no. 02-34, July, 2002.

DAVIDSON, Paul. Post keynesian macroeconomic theory: a foundation for successful economic policies for the twenty-first century. London: Edward Elgar. 1994.

DAVIDSON, Paul. Money and the real world. 2nd edition. Londres: MacMillan, 1978.

Dos SANTOS, Gustavo Antônio Galvão. Uma releitura da Teoria das Finanças Funcionais. Tese defendida como requisito parcial à obtenção do título de Doutor em Economia, junto ao Instituto de Economia da Universidade Federal do Rio de Janeiro, 2005.

FORSTATER, Mathew. LERNER, Abba Ptachya (1903-1982). Working Paper No. 52. Center for Full Employment and Price Stability. April 2006.

FORSTATER, Mathew. "Functional finance and full employment: lessons from Lerner for today". The Jerome Levy Economics Institute of Bard College, Working Paper No. 272, 1999.

FRIEDMAN, Milton. Capitalismo e liberdade. 2a. ed. São Paulo: Nova Cultural, 1985.

FRIEDMAN, Milton. "The role of monetary police”. American Economic Review, March, 1968.

FRIEDMAN, Milton.The quantity theory of money — a restatement. In: Milton Friedman (org.) Studies in the quantity theory. Chicago: Chicago University Press, 1956, p. 3-21.

KREGEL, Jan. Budget deficits, stabilization policy and liquidity preference: Keynes's post war policy proposals. In: VICARELLI, F. Keynes's relevance today. London: MacMillan, 1985.

LERNER, Abba P. Economics of employment. NY: McGraw-Hill, 1951. Disponível em http://www. questia.com/library/book/economics-of-employment-by-abba-p-lerner-seymour-e-harris.jsp.

LERNER, Abba P. Money as a creature of the State. American Economic Review, v. 37, n. 2, p. 312-317, May 1947.

LERNER, Abba P. "Function Finance and Federal Debt". Social Research, v. 10, n. 1, Feb. 1943, pp. 38-51. Disponível em http://k.web.umkc.edu/keltons/Papers/501/functional\%20finance.pdf.

LERNER, Abba P. The Economic Steering Wheel. The University Review, (Kansas City), June 1941.

LIMA, Gilberto Tadeu de. Em busca do tempo perdido: a recuperação pós-keynesiana da economia do emprego de Keynes. Rio de Janeiro: BNDES, 1992.

LUCAS, Robert. "Some international evidence on output-inflation trade-offs". American Economic Review, v. 63, June 1973.

LUCAS, Robert e SARGENT, Thomas (ed.) Rational expectations e econometric practice. Minneapolis: University of Minnesota Press, 1981.

NELL, Edward. J.; FORSTATER, Mathew. Reinventing Functional Finance: transformational growth and full employment. Northampton, MA: Edward Elgar Publishing, 2003.

OREIRO, José Luís e De PAULA, Luiz Fernando. Keynes, política fiscal e a economia brasileira. Valor Econômico, 5 de março de 2009.

RODRIGUES, Roberto. O déficit público de alto emprego: uma aplicação para o caso brasileiro. Dissertação submetida à Faculdade de Economia da Universidade Federal Fluminense. Niterói, Dezembro 2004.

WRAY, L. Randall. Trabalho e moeda hoje: a chave para o pleno emprego e a estabilidade dos preços. Rio de Janeiro: UFRJ/Contraponto, 2003.

WRAY, L. Randall. Senhoriagem ou soberania? Economia e Sociedade, Campinas, v. 11, n. 2 (19), p. 193-211, jul.-dez. 2002. 